\title{
GUIDELINES FOR A DIGITAL REINTERPRETATION OF ARCHITECTURAL RESTORATION WORK: REALITY-BASED MODELS AND REVERSE MODELLING TECHNIQUES APPLIED TO THE ARCHITECTURAL DECORATION OF THE TEATRO MARITTIMO, VILLA ADRIANA
}

\author{
B. Adembri ${ }^{\text {a }}$ L. Cipriani ${ }^{b}$, G. Bertacchi ${ }^{\mathrm{c}, *}$

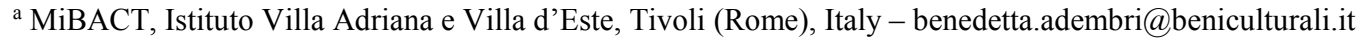 \\ ${ }^{b}$ Dept. of Architecture, Alma Mater Studiorum University of Bologna, Italy - luca.cipriani@unibo.it \\ c Scuola di Specializzazione in Beni Architettonici e del Paesaggio, University of Florence, Italy - gianna.bertacchi@unifi.it
}

KEY WORDS: Digital Photogrammetry, Laser Scanning, Reverse Modelling, Best Fitting Circumferences, 3D models, Virtual Restoration, Virtual Anastylosis, Teatro Marittimo

\begin{abstract}
:
The Maritime Theatre is one of the iconic buildings of Hadrian's Villa, Tivoli. The state of conservation of the theatre is not only the result of weathering over time, but also due to restoration work carried out during the Fifties of the past century. Although this anastylosis process had the virtue of partially restoring a few of the fragments of the compound's original image, it now reveals diverse inconsistencies and genuine errors in the reassembling of the fragments. This study aims at carrying out a digital reinterpretation of the restoration of the architectural fragments in relation to the architectural order, with particular reference to the miscellaneous decoration of the frieze of the Teatro Marittimo (vestibule and atrium).

Over the course of the last few years the Teatro Marittimo has been the target of numerous surveying campaigns using digital methodology (laser scanner and photogrammetry SfM/MVS). Starting with the study of the remains of the opus caementicium on the ground, it is possible to identify surfaces which are then used in the model for subsequent cross sections, so as to achieve the best fitting circumferences to use as reference points to put the fragments back into place.
\end{abstract}

\section{INTRODUCTION}

The so-called Maritime Theatre is one of the most renowned buildings of Hadrian's Villa and perhaps the best known worldwide. Its fame dates back to the Renaissance period and is mainly due to its interesting and peculiar plan design, that is a sort of re-interpretation of the classic Roman domus that Hadrian wanted to be shaped into an unconventional circular shape (the island) surrounded by a portico (MacDonald and Pinto, 1995). The construction of this building is considered to be part of the first constructive phase (118-121 A.D.) of the whole architectural complex, together with the Heliocaminus Baths, as confirmed by the brick stamps found (Figure 1).

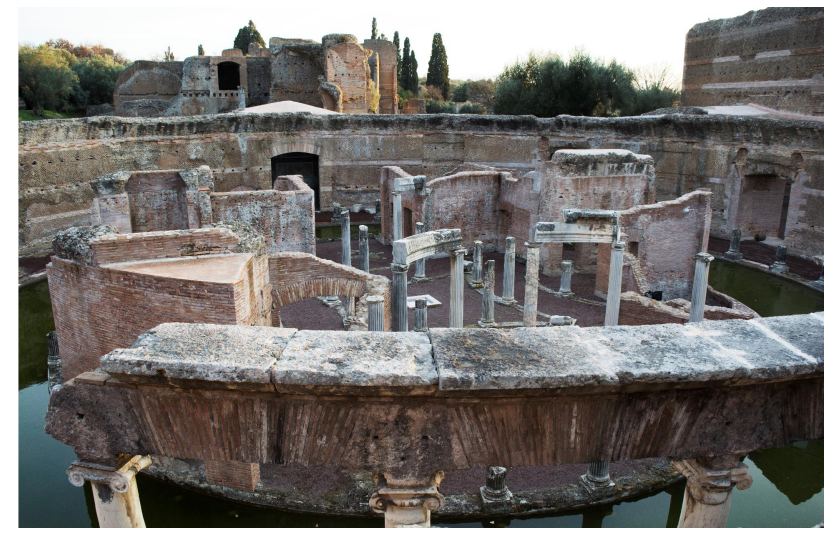

Figure 1. Overall view of the Maritime Theatre

The spaces of the Maritime Theatre perform the same function of those of a Roman domus (atrium, tablinum, cubicles, tricliniar area, baths, lavatories), although they differ in shape and plan layout, creating an unique system in the architecture of the Roman Empire: the built area (covering approximately 314 square meters) develops in the so-called "island", circular in shape, surrounded by a water canal, delimited by an annular portico, originally barrel-vaulted and supported by 40 ionic columns made in marble from Karystos.

The island domus presents a curvilinear vestibule giving access to an atrium with mixtilinear plan, in the centre of which a fountain was placed, surrounded by a porticoed ambulatory overlooked by residential environments: two rooms along the eastern side and a thermal bath for the exclusively use of the emperor on the opposite side, whereas on the southern side there were the main rooms; both the rooms and the bath had a private lavatory.

One of the most valuable elements of the building on the island is represented by the figurative reliefs that decorate the mixtilinear trabeations, characterized by the presence of carved figures both on the concave and on the convex side. Surprisingly the frieze had been carved directly on the trabeation instead of being sculpted on a different element, as was more usual at that time: the subject depicted, with Erotes and other mythological creatures as protagonists, refers to seathiasos and chariot races, whose refinement and originality arose the interest of artists and patrons since the Renaissance, a period of rediscovery of Hadrian's Villa.

Among those, the architect Pirro Ligorio was one of the first who studied the complex of the Villa, and in particular the Maritime Theatre and Piazza d'Oro, impressed by its refined decorations: some of the friezes were reused in the fountains of Villa d'Este that Pirro Ligorio designed for Cardinal Ippolito II

* Corresponding author 
d'Este (Adembri, 2013). In fact, the fortune of the relief decorations from Hadrian's Villa determined in many cases the cutting of the figurative portion from the entablature aiming at their reuse in other buildings or monuments.

Over the centuries, other researchers were touched by the beauty of the Maritime Theatre: their descriptions and their drawings are now of tremendous importance to determine its state of conservation in the past (Contini, Piranesi, Penna, some of the Pensionnaires of the Académie de France in Rome).

Many of them have ventured even to imagine the ancient colours of the buildings, first among them the students at the French Academy in Rome (Esquié, Daumet) and more recently Üblacker, who carried out an accurate study proposing an hypothetical reconstruction of the elevations (Üblacker, 1985).

The current state of conservation of the Maritime Theatre is due to not only to the passing of time, but it is also the result of various restoration works, carried out starting from the end of the $19^{\text {th }}$ century and then in the Fifties by Pietro Romanelli e Italo Gismondi, who partially restored the portico carrying out the anastylosis of some columns and the reconstruction of part of the vaulted space.

A subsequent restoration intervention by Salvatore Aurigemma, between 1957 and 1958 (Aurigemma, 1961), dealt with the columns of the island. During this work, the missing parts of the ribbed marble columns and some sections of the entablature were reconstructed with reinforced concrete, in order to replace some fragments of the figured marble friezes. Although this anastylosis process has been based on data from direct examination of the site (e.g. the height of the columns could be deduced from stone elements inserted in the masonry in correspondence to the trabeation's extremity), it now reveals inconsistencies and genuine errors in the reassembling and replacing of the fragments (Figure 2).

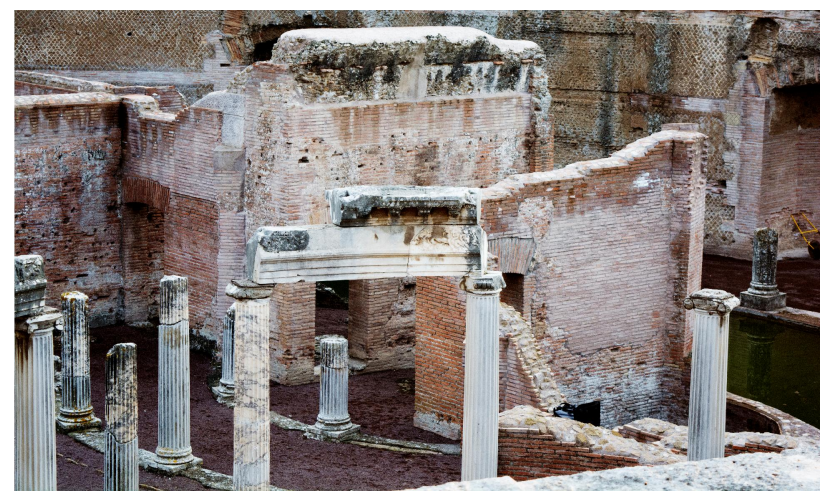

Figure 2. Picture of the reconstructed entablature with friezes

Therefore, the need of an overall re-reading of the order and placement of the friezes in the light of new available data is compelling. In recent years, in fact, the Maritime Theatre, as well as many other parts of the Villa, has been subject to several surveying campaigns, carried out through active sensors technology with the use of 3D laser scanner, and additional measurement campaigns by means of digital photogrammetry (Cipriani and Fantini, 2017).

The availability of these three-dimensional models allowed determining - with greater reliability and precision than ever before - the radius of curvature of the remains of the ancient masonry and the classical order, with the aim to understand the original location of the decorated entablatures. The comparison of this radius with those extracted from the still existing friezes helps hypothesising a possible repositioning with high degree of reliability thanks to the digital technology (Adembri et al., 2015).
The present research deals with a series of relevant current topics ranging from contemporary acquisition technologies, to restoration and critical analysis of previous interventions, in such a way as to define robust pipelines for the achievement of coherent virtual reassembling of fragments (Scopigno et al., 2011).

In the last years two main categories emerged from the panorama of scientific papers centred on these themes: the first approach focuses on the integration of different cultural and technical knowledge ranging from archaeology, philology, restoration, computer science, digital surveying, 3D modelling (Thuswaldner et al., 2009; Ippolito, 2015; Canciani et al., 2013), while the second mainly deals with the exclusive use of formal features to drive automatic matching among scattered and fragmented elements of decoration and masonry in general (Vendrell-Vidal and Sánchez-Belenguer, 2014).

In short, the interdisciplinary methodology used in this research, examined in depth in the following sections, is as follows:

- Determination of the radius of curvature obtained by the arithmetic mean of the radii extracted from the traces of the ancient masonry of the global model;

- Determination of the radius of curvature obtained by the arithmetic mean of the radii extracted from various sections of the analysed friezes;

- Comparison between the two radii of curvature.

Starting from this comparison, and taking into account the possible inaccuracies due to adjustments during the original construction and to alterations during cutting off and splitting up the friezes, the original location has been supposed with the support of the composition of the two decorative themes (chariot races and sea-thiasos).

\section{METHODOLOGY}

\subsection{Friezes conservation and digital survey}

Starting from the Fifties, finds from excavations were preserved in various archaeological areas of the Villa. Such finds comprise a very considerable number of often highly fragmentary pieces, never properly identified or catalogued. Quite recently, with a view to the logistic rearrangement of items and to ascertaining the Villa's stock of archaeological assets, a scientific study was launched, involving several categories of the most numerous items kept at the so-called Cento Camerelle warehouse.

Among the stored items, there are several figured friezes with a characteristic curvilinear shape, belonging to the Maritime Theatre, some of which were subjected to anastylosis operations in 1957/1958 and have been replaced inside the building, while others can be found in public and private collections, both in Italy and elsewhere in Europe. One fragment is preserved at London's British Museum (n. 2319), a further three are found at the Louvre Museum in Paris (MA 151; MA 1575; MA 152); two fragments are kept in the Vatican Museums (n. 1610; n. 364). Yet another fragment is in Liverpool, at the Merseyside County Museum; two others are preserved at the Berlin Staatliche Museen (n. 934; n. 904). Three other fragments have been employed in the masonry of Villa Doria Pamphili in Rome. We also have information about at least four other fragments preserved on properties in the Tivoli area, to which a further small fragment can be added, identified in September 2009 by the author on a private property close to the Villa Adriana archaeological area. 
At the base of this research there is a complete digital model of the entire complex of the Maritime Theatre that allows both to extrapolate data using reverse modelling methodology, and to relocate the friezes (Cipriani and Fantini, 2017).

For the purposes of this study, the global model has been used as a reference basis for the extrapolation of the circumferences related to the original parts of the building, today still visible. The High-Poly or master digital models (Apollonio et al., 2010) of the friezes, both kept in situ and stored in museums, were carried out to extrapolate the best fitting circumferences and compare them with those previously obtained.

The digital model of the Maritime Theatre is the result of a research started with a first survey campaign in 2009 that had gradually integrated partial mesh obtained from digital photogrammetric survey to the global model obtained by laser scanner survey.

Up to now, several - but partial - laser scanner surveys of the building are available: the first, carried out in 2006 by the Università Politecnica delle Marche (DARDUS), while the second, carried out in 2009 by the University of Florence (Architectural Design Dept.), relates exclusively to the island. As far as the architectural decoration is concerned, we have laser scanner models both of the friezes preserved in situ, and those at the Villa Adriana Didactic Museum. In winter 2013, the island was surveyed entirely with a photogrammetric and laser scanner campaign, which allowed completing the global model with the missing parts of the architecture (Dept. of Architecture, University of Bologna).

Lately (February 2017), the marble friezes stored in the Canopus Antiquarium of the Villa have been surveyed again by the authors with a further photogrammetric campaign, in order to obtain digital high-detailed models from SfM-MVS methodologies. Particular attention was paid to lighting control during the data acquisition phase: two studio lamps with a total of $8 \times 36 \mathrm{~W}$ daylight fluorescent lamps have been used, with two softboxes $60 \times 60 \mathrm{~cm}$ in order to avoid spots of shadows on the figured friezes surface that might generate data acquisition errors and sharp shadows in the final texture (Figure 3).

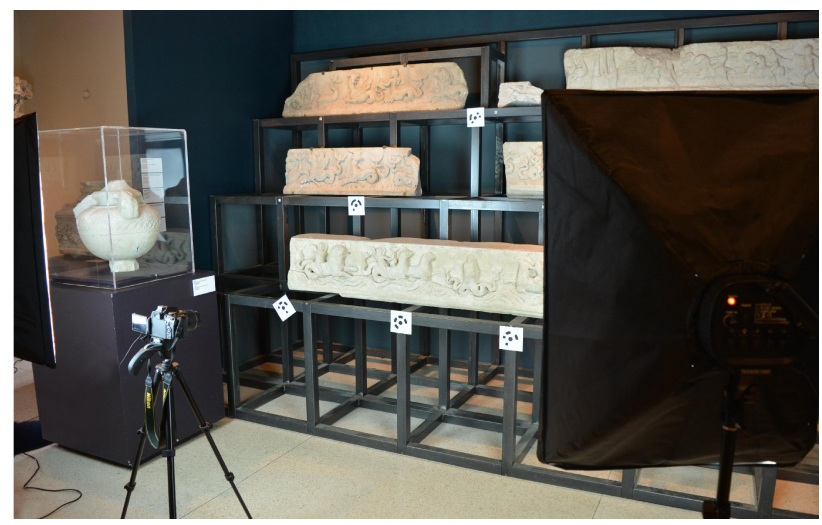

Figure 3. Image acquisition with reflex camera on tripod: construction of a set for a better lighting control

\subsection{Circumferences from the global model of the Theatre}

Only the meshes that concerned the base column slabs and the remains of the opus caementicium on the ground under the entablature have been considered in the global model of the Maritime Theatre, in order to extrapolate the best fitting circumferences.
The meshes were divided according to semantic parameter concerning the order disposition (bases, columns, walls, entablatures), to extract a best fitting circumferences from each category (Cipriani and Fantini, 2017) (Figure 4).

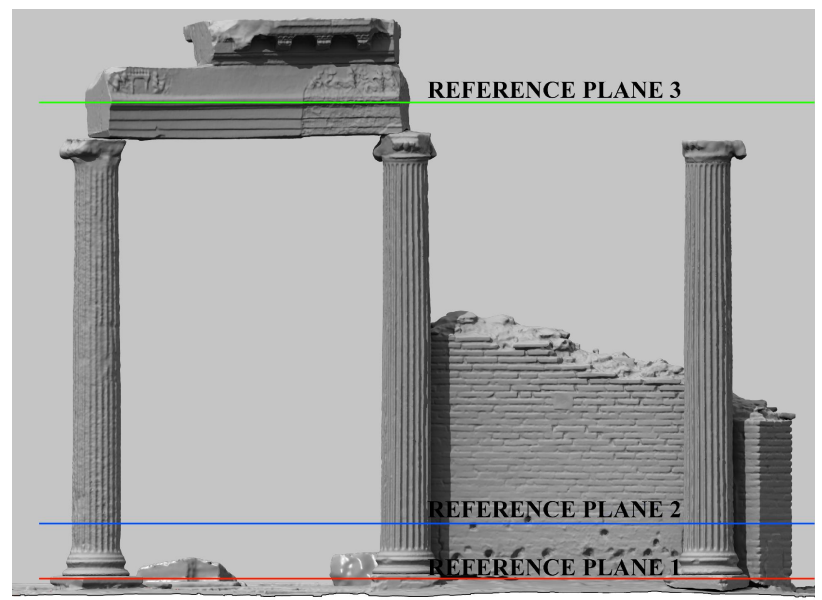

Figure 4. Reference planes at different levels for best fitting circumference's extraction

This operation, seemingly redundant, is fundamental to determine with accuracy the centre and the radius of the circumference used during construction, that might oscillates due to time alterations and restoration works.

From the analysis carried out and the comparison between the circumferences, we can immediately notice that the circumference related to the reconstructed entablature is incompatible respect of the other ones.

For each bend this operation has been disposed on the internal and the external side to obtain a final circumference to compare with the frieze bending (Figure 5 and Table 6).

\begin{tabular}{|c|c|c|c|c|}
\hline LOCATION & ID & $\begin{array}{c}\text { Center position } \\
(\mathrm{mm})\end{array}$ & $\begin{array}{c}\text { Radius } \\
(\mathrm{mm})\end{array}$ & \begin{tabular}{|c|} 
Radius \\
(roman feet) \\
\end{tabular} \\
\hline \multirow{6}{*}{$\begin{array}{l}\frac{\mathbb{I}}{E} \\
\text { o } \\
\text { Z }\end{array}$} & N-B-1 & $-10658,8606,-5903,6654$ & 7873,6366 & 26,6361 \\
\hline & N-B-2 & $-10749,9661,-5965,288$ & 7458,5408 & 25,2319 \\
\hline & $\mathrm{N}-\mathrm{W}-3$ & $-10412,1831,-5839,4895$ & 5584,0578 & 18,8906 \\
\hline & N-B-4 & $-10427,6333,-5856,4641$ & 5176,0943 & 17,5105 \\
\hline & $\mathrm{N}-\mathrm{W}-5$ & $-10448,3628,-5851,437$ & 5070,3660 & 17,1528 \\
\hline & N-B-6 & $-10396,3993,-5827,5827$ & 4614,7775 & 15,6116 \\
\hline \multirow{4}{*}{ 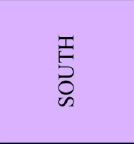 } & S-B-1 & $7241,0164,3857,469$ & 7367,0000 & 24,9222 \\
\hline & S-B-2 & $7241,0164,3857,469$ & 6811,4940 & 23,0429 \\
\hline & S-B-3 & $7563,7606,4086,0529$ & 5189,6612 & 17,5564 \\
\hline & S-B-4 & $7641,6791,4122,952$ & 4740,3071 & 16,0362 \\
\hline \multirow{6}{*}{$\sum_{4}^{5}$} & E-B-1 & $-5958,0501,7328,8481$ & 6778,5000 & 22,9313 \\
\hline & E-B-2 & $-5958,0501,7328,8481$ & 6242,7203 & 21,1188 \\
\hline & E-B-3 & $-6135,6917,7467,2501$ & 4492,7724 & 15,1988 \\
\hline & E-B-4 & $-6135,6917,7467,2501$ & 3982,7724 & 13,4735 \\
\hline & E-B-5 & $-5480,5022,6403,072$ & 4083,0000 & 13,8126 \\
\hline & E-B-6 & $-5480,5022,6403,072$ & 3499,3691 & 11,8382 \\
\hline \multirow{4}{*}{$\begin{array}{l}\sqrt[5]{n} \\
\frac{11}{3}\end{array}$} & W-B-1 & $3300,2085,-9255,5221$ & 6977,0000 & 23,6028 \\
\hline & W-B-2 & $3300,2085,-9255,5221$ & 6443,9395 & 21,7995 \\
\hline & W-B-3 & $3136,5547,-9184,0762$ & 4310,5662 & 14,5824 \\
\hline & W-B-4 & $3156,3821,-9128,2239$ & 3794,1992 & 12,8356 \\
\hline
\end{tabular}

Table 6 . Table with values for the analysed radii 


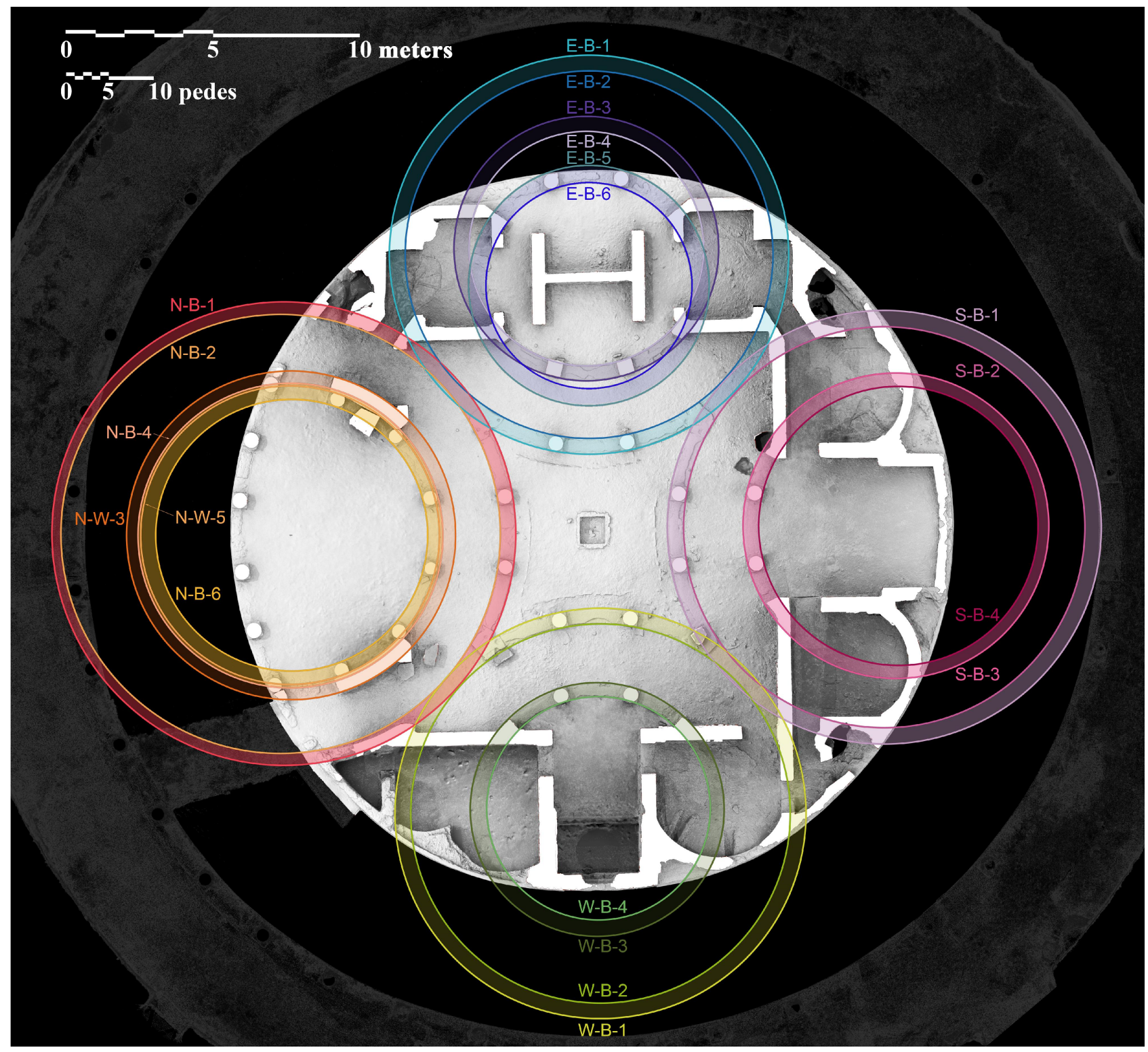

Figure 5. Plan with the indication of the codes and the positions of the circumferences

\subsection{Circumferences by friezes}

A precise series of operations has been realized on each frieze that has at least one digital model available. These operations were performed on the mesh with state-of-art software for reverse modelling, Geomagic Design X 2016, generally used in mechanical engineering to extrapolate sections, in order to extrude and combine them obtaining a solid model.

Recently several digital models of some of the friezes have been produced during the latest survey campaigns. Some of them derived from the union of numerous range maps, other from photogrammetric survey. To have more control over the selection of the final best fitting circumference, the analytical procedure has been repeated on the two models, if available, the first ones obtained from SfM/MVS, the other ones from single range maps from a laser fringe system. The different point cloud scans have been realigned, using the photogrammetric model as a reference, in order to avoid the usual distortion effect produced by ICP algorithms, when they are applied to a several number of objects with range maps having a linear trend (Guidi et al., 2010).

To generate a best fitting circumference, first of all we need to operate a section on the mesh in respect to a predefined plane. The first step concerns the choice of this specific plane: we know for sure that the friezes were carved and divided into small parts since the sixteenth century to be ready for reuse. These operations created new surfaces, different and maybe not parallel to the original lower surface in contact with the bearing plane of the columns. Moreover, if the frieze is oriented on the vertical axis not in a proper way respect to the original plane, the final circumference may vary of several centimetres (Figure 7).

However, one can notice some anomalies in the decoration: for example, the upper cornice of the TM_01 frieze has an inclination angle of 0.5 degrees in respect to the section obtained by the upper plane, chosen as the reference plane because of his belonging to the original stonework (Figure 8). 


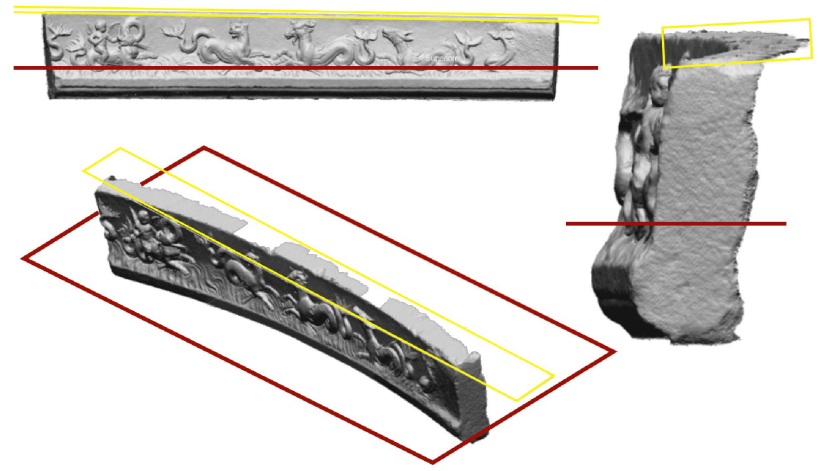

Figure 7. Different sections of the frieze depending on the selected reference plane (examples yellow and red planes)

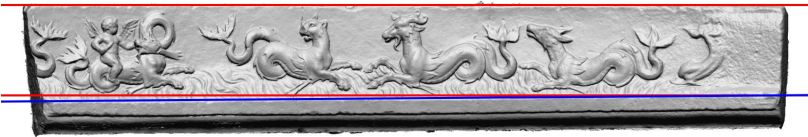

Figure 8. The main front of the frieze with the misalignment between the upper plane (red) and the cornice (blue)

Once the plane has been set out and copied at least in three different positions, included in the upper cornice (always present in all the fragments), each plane was a reference for a specific section of the mesh. Each temporary section (template) has been the basis for the creation of a circumference selecting portions of the section. Subsequently it has been considered an average of the length of the three radii obtained from the respective cut-planes.

Once we had the centre of the circumference and the average radius, it has been possible to define a circumference for each frieze, in order to compare the gathered information with the ones from the global model (Figure 9).

\subsection{Comparison and replacing hypothesis}

Starting from the collected data, it has been possible to develop a hypothesis about the original position of the friezes, understanding the general position of the decoration themes.

The comparison between the two circumferences (the one obtained by the frieze and the other by the model) allowed to replace friezes along the curve that better fits the bending radius of each decorated relief (Table 10).

The comparison has considered as compatible those values of the radii included in a neighbourhood of the value of the circumference obtained by the model, considering a radius variation of $+/-3$ percentage points. The difference between radii can be due to the past restoration works, to the length of the frieze in relation to the total length of circumference or to the union of separated fragments, which can affect the original bending radius.

This was not the only data used for repositioning: further useful information can be obtained from the analysis of the decorative system by observing the friezes:

- Most of the friezes conserve both convex and concave sides depicting the sea-thiasos, while only one frieze represents different themes on its opposite carved faces, i.e. chariot races and sea-thiasos. There is no evidence of fragments decorated with chariot races on both sides;

- Some friezes depict motives of chariot races showing representations of elements like metae (TM_03) and carceres (TM 06), that helped defining their original position;
Similarly, some friezes with the maritime decoration represent a dolphin that marks the beginning of the decoration (TM_01; TM_07a).

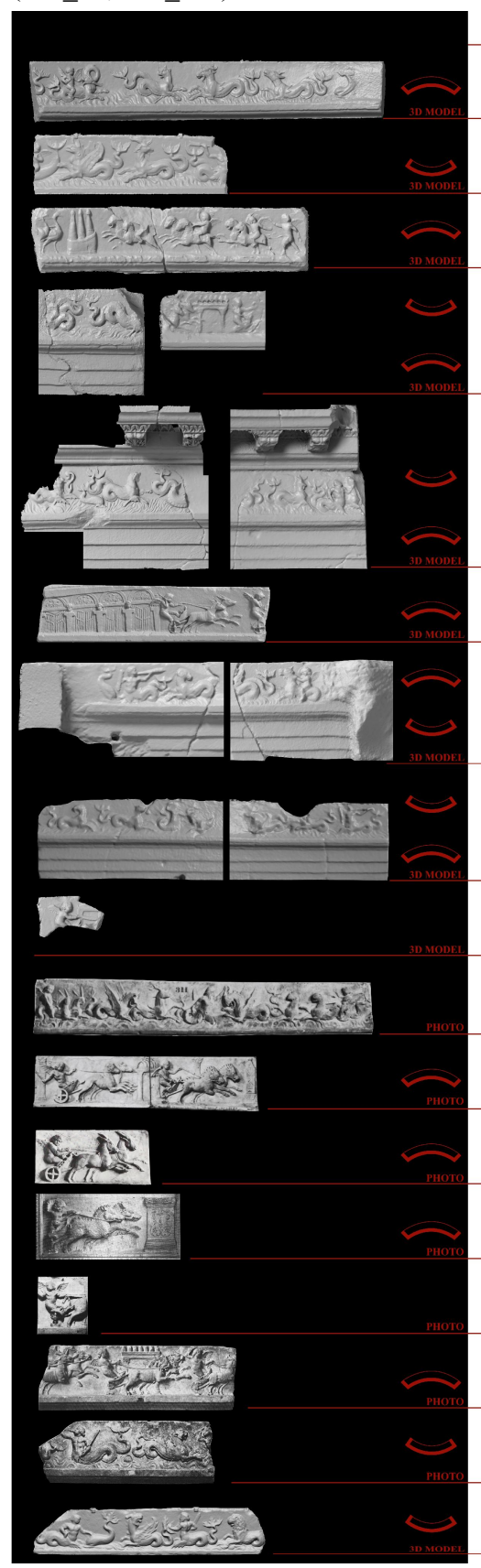

\begin{tabular}{|c|c|}
\hline $\begin{array}{l}\text { Name / Curvature / } \\
\text { Present location }\end{array}$ & $\begin{array}{l}\begin{array}{l}\text { Figured cycles } \\
\text { (front/ rear) }\end{array} \\
\text { (t) }\end{array}$ \\
\hline $\begin{array}{l}\text { TM_01 } \\
\text { Hadriar' Villa, Canopus } \\
\text { Antiquarium (n. 1147770) }\end{array}$ & $\begin{array}{l}\text { Sea-Thiasos / } \\
\text { slab }\end{array}$ \\
\hline 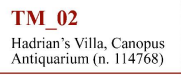 & $\begin{array}{l}\text { Sea-Thiasos/ } \\
\text { slab }\end{array}$ \\
\hline $\begin{array}{l}\text { TM_03 } \\
\text { Hadrian'svilla, Canopus } \\
\text { Antiquarium }\end{array}$ & $\begin{array}{l}\text { Chariot Race/ } \\
\text { slab Rot }\end{array}$ \\
\hline 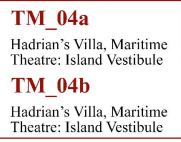 & $\begin{array}{l}\text { Sea-Thiasos } \\
\text { Chariot tace }\end{array}$ \\
\hline 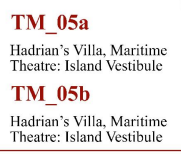 & Sea-Thiasos \\
\hline 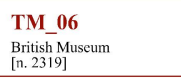 & $\begin{array}{l}\text { Chariot Race/ } \\
\text { slab }\end{array}$ \\
\hline $\begin{array}{l}\text { TM_07a } \\
\text { Hadrian's VVilla, Maritime } \\
\text { Theatre: Tablinum Portico } \\
\text { TM_07b } \\
\text { Hadrian's Villa, Maritime } \\
\text { Theatre: Tablinum Portico }\end{array}$ & Sea-Thiasos \\
\hline $\begin{array}{l}\text { TM_08a } \\
\text { Hadrian's Villa, Maritime } \\
\text { Theatre: Vestibule } \\
\text { TM_08b } \\
\text { Hadraiar's Villa, Maritime } \\
\text { Theatre: Vcstibule }\end{array}$ & $\begin{array}{l}\text { Sea-Thiasos } \\
\text { Sea-Thiasos }\end{array}$ \\
\hline $\begin{array}{l}\text { TM_09 } \\
\text { Hadrian's Villa, Canopus } \\
\text { Antiquarium (n. 403) }\end{array}$ & Chariot Race \\
\hline $\begin{array}{l}\text { TM_10 } \\
\text { Merseyside County } \\
\text { Museums, Liverpool }\end{array}$ & Sea-Thiasos \\
\hline 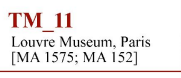 & Chariot Race \\
\hline $\begin{array}{l}\text { TM_12 } \\
\text { Loure Museum, Paris } \\
\text { [MA III] }\end{array}$ & Chariot Race \\
\hline $\begin{array}{l}\text { TM_13 } \\
\text { Vatican Museum, Rome } \\
\text { n. } 364\end{array}$ & Chariot Race \\
\hline $\begin{array}{l}\text { TM_14 } \\
\text { Vatican Museum, Rome } \\
\text { n. } 1610\end{array}$ & Chariot Race \\
\hline $\begin{array}{l}\text { TM_15 } \\
\text { Staatliche Muscen, Berlin } \\
\text { [SK 904] }\end{array}$ & Chariot Race \\
\hline $\begin{array}{l}\text { TM_16 } \\
\text { Staatliche Museen, Berlin } \\
\text { [SK 934] }\end{array}$ & Sea-Thiasos \\
\hline $\begin{array}{l}\text { POS_01 } \\
\text { Hadrian's Villa, Canopus } \\
\text { Antiquarium }\end{array}$ & 勇ea-Thiasos, \\
\hline
\end{tabular}

Figure 9. Catalogue of the existing friezes and their actual location, curvature and dimensional information

In other cases, it was useful to consider the interaxle spacing between columns to exclude or confirm the possible arrangement of decorated elements. It is the case of the frieze TM 01 that presents a radius compatible with two circumferences (N-B-6 and S-B-4), but the second one can be excluded: in fact the length of the frieze is bigger than the limited interaxle spacing of the first intercolumnio starting from the right. The TM_01 frieze was placed upon the second intercolumniation in the right side of the Vestibule, since the first one has a different curvature: this point is the connection between the Vestibule and the entablature of the side facing the euripus. 


\begin{tabular}{|c|c|c|}
\hline & $\begin{array}{l}\text { Laser scanner model } \\
\text { radius (mm/ Roman feet) }\end{array}$ & $\begin{array}{l}\text { Photogrammetric model } \\
\text { radius (mm / Roman feet) }\end{array}$ \\
\hline \multirow[t]{2}{*}{ TM_01 } & $\begin{array}{l}4425 \mathrm{~mm} \\
4683 \mathrm{~mm} \\
4746 \mathrm{~mm}\end{array}$ & $\begin{array}{l}4533 \mathrm{~mm} \\
4564 \mathrm{~mm} \\
4708 \mathrm{~mm}\end{array}$ \\
\hline & $4618 \mathrm{~mm} / 15,62$ R. f. & $4601 \mathrm{~mm} /$ 15,54 R. f. \\
\hline \multirow[t]{2}{*}{ TM_02 } & $\begin{array}{l}4875 \mathrm{~mm} \\
4897 \mathrm{~mm} \\
4912 \mathrm{~mm}\end{array}$ & $\begin{array}{l}4935 \mathrm{~mm} \\
4980 \mathrm{~mm} \\
4997 \mathrm{~mm}\end{array}$ \\
\hline & $4894 \mathrm{~mm} /$ 16,55 R. f. & 4971 mm / 16,81 R. f. \\
\hline \multirow[t]{2}{*}{ TM_03 } & $\begin{array}{l}7169 \mathrm{~mm} \\
6989 \mathrm{~mm} \\
7125 \mathrm{~mm}\end{array}$ & $\begin{array}{l}7256 \mathrm{~mm} \\
6932 \mathrm{~mm} \\
7021 \mathrm{~mm}\end{array}$ \\
\hline & 7094 mm / 23,99 R. f. & 7069 mm / 23,91 R. f. \\
\hline \multirow[t]{2}{*}{ TM_05a } & $\begin{array}{l}4201 \mathrm{~mm} \\
4226 \mathrm{~mm}\end{array}$ & \\
\hline & $4213 \mathrm{~mm} / 14,21$ R. f. & \\
\hline \multirow[t]{2}{*}{ TM_06 } & $\begin{array}{l}6130 \mathrm{~mm} \\
6170 \mathrm{~mm} \\
6245 \mathrm{~mm}\end{array}$ & \\
\hline & $6181 \mathrm{~mm} / 20,91$ R. f. & \\
\hline
\end{tabular}

Table 10. Table with radii of analysed friezes

The TM_03, a concave frieze representing chariot races, has a bending radius compatible with the northern and the southern sides of the atrium (N-B-2; S-B-2). Probably its original position was set with the metae in the middle part of the central intercolumniation, since the metae were the focal point of the entire symmetric decoration of each side. As evidence of this, one can consider the distance between the metae and the right side of the frieze as one half of the entire frieze, and then comparing this length with the half of the interaxle spacing, noticing that the difference is maximum 3-4 centimetres.

The TM_06 is compatible with the eastern and western side of the atrium (E-B-2; W-B-2) and, according to the decoration motives, it can be positioned in the left side. The two circumferences are different because the central shape is a rectangle (Adembri et al., 2015) and not a square as supposed by Üblacker (1985). In his hypothesis there are several differences in the repositioning of the friezes. The fragment POS_01, attributed by Üblacker in N-B-4 or S-B-3, is compatible with E-B-3, but the decoration style is not pertinent with the Maritime Theatre, and it probably belongs to Piazza d'Oro (Figure 11).

The curvature of TM_04 is difficult to identify with precision, due to the little length of the fragment. The frieze is important overall for his dual decoration (sea-thiasos and chariot races). It might be positioned in the central atrium (Figure 12).

\section{CONCLUSIONS}

The methodology adopted is based as much as possible on the objectivity of the collected data, starting from the digital survey that is a high-detailed representation of the real geometry.

In the last years a new investigation line has given proof of high interest since revised or confirmed the reliability of previous historic surveys and geometric analysis on relevant ancient buildings introducing workflows coming from the field of reverse modelling and applied to complex objects, in particular domes and cupolas (Aita et al., 2017; Cipriani et al., 2016).

Diverse inconsistencies and genuine errors in the reassembling of the fragments are due to the lack of specific survey instrument and digital data, as the reality-based models are. The circumference related to the reconstructed entablature is in fact quite discordant in respect of other circumferences (Figure 13). This last aspect - the comparison with former graphic outputs obtained by means of dated surveying technologies - is just a part of a comprehensive cultural development phenomenon that some researchers are trying to revitalize while trying to track down ideal designing geometries on accurate digital surveys on "as-built" heritage (Adembri et al., 2015).

The quantitative approach chosen for the analysis carried out fits well with the mixtilinear architecture typology. The entire procedure is the result of only a partial automation, since it is necessary an interdisciplinary and constant control over the phases of the process. The combination of expertise from different disciplines is deeply involved in this mechanism, such as the collaboration between architects and archaeologists.

The result of the interdisciplinary cooperation is a digital model, containing information, allowing a continuous development of the knowledge about the specific cultural heritage.

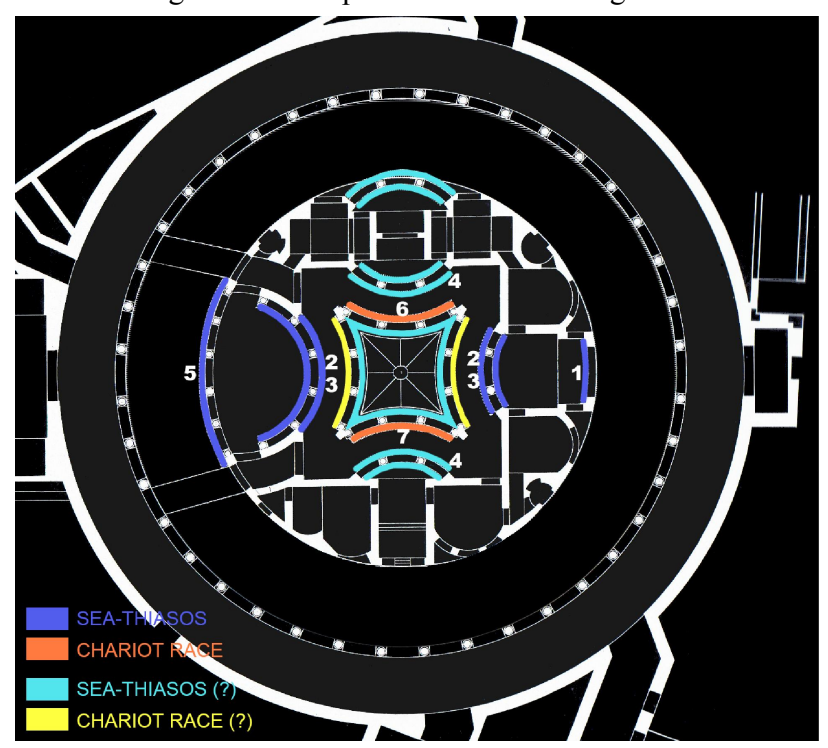

Figure 11. Üblacker's hypothesis about the position of the friezes. Edited image from Üblacker, 1985: 1) [TM_01] - Röm.

Kunsthandel; 2) [POS 01] - Sammlung Lansdowne - radius $4.75 \mathrm{~m}$; 3) [TM_02] - Sammlung Lansdowne - radius $4.75 \mathrm{~m}$; 4) [TM_16] - Berlin 934 -radius $6.60 \mathrm{~m}$; 5) [TM_10] - Ince Blundell Hall - radius 11.25 m; 6) [TM_15] - Berlin 904 radius $6.10 \mathrm{~m}$; 7) [TM_06] - British Museum 2319 - radius

$$
6.30 \mathrm{~m}
$$

The result leads to virtual anastylosis, without causing damage to existing structures. In fact, restoration works are never completely reversible and actually providing numerous benefits: - In-depth studies made possible without having to physically work on the artefact (except for surveying operations) thus limiting the possibility of damage of the ancient structure;

Simultaneous studies by using the digital data produced operated by different research groups from various disciplines (archaeology, restoration, architecture, etc.);

Digital models of artefacts, displaced over the centuries from their original site and at present preserved in various museums or private collections around the world, can now be virtually put together for study purposes;

- Starting from the digital model, one can now replicate the missing parts and the complementary part of an ancient fragment in 1:1 scale;

- Facilitating preparations of restoration works or implementation of copies with the consequential musealization of the originals;

Possibility to use the copies for setup in temporary exhibition or loans (Figure 14). 


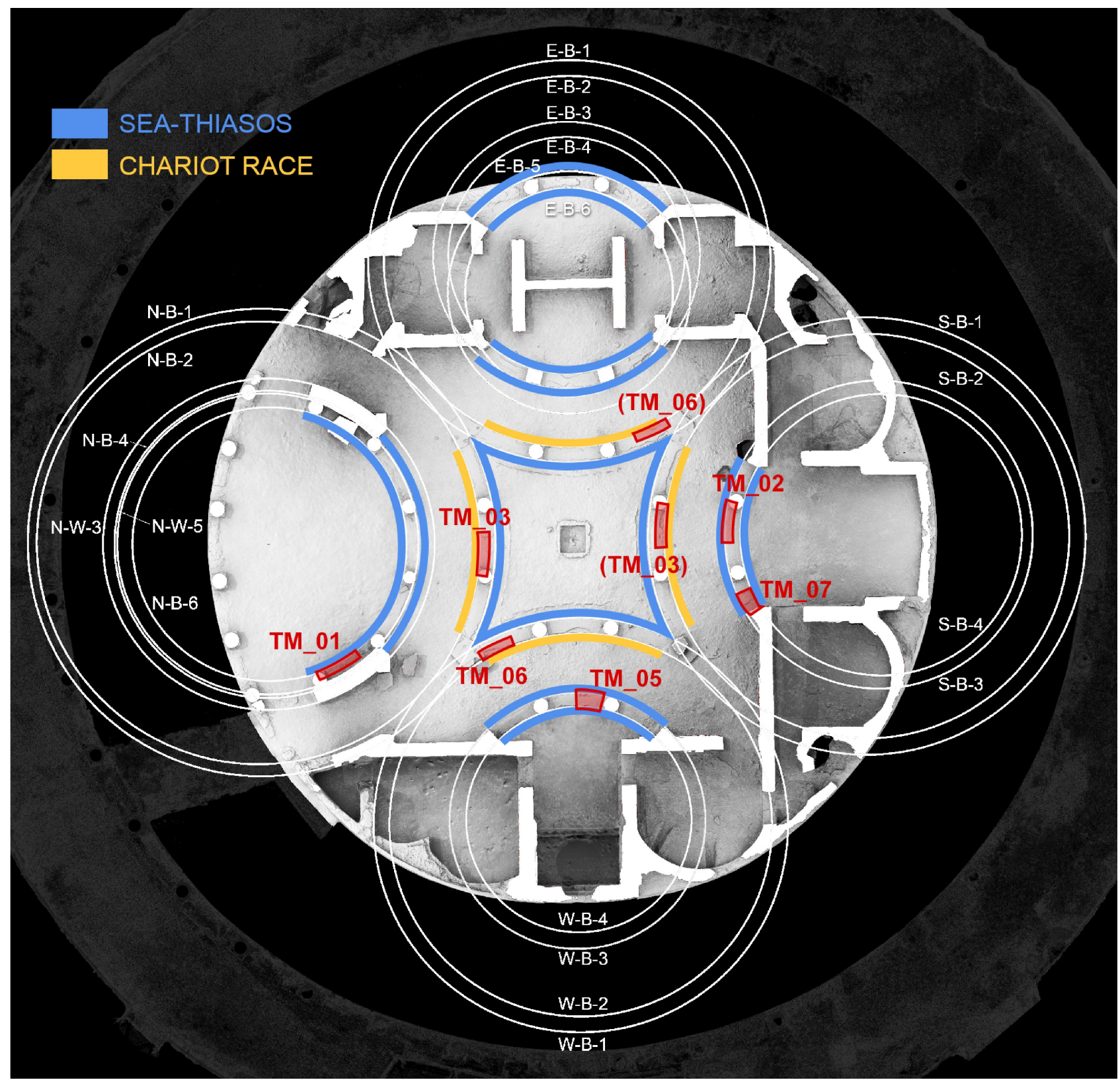

Figure 12. Plan with the friezes in his supposed original position

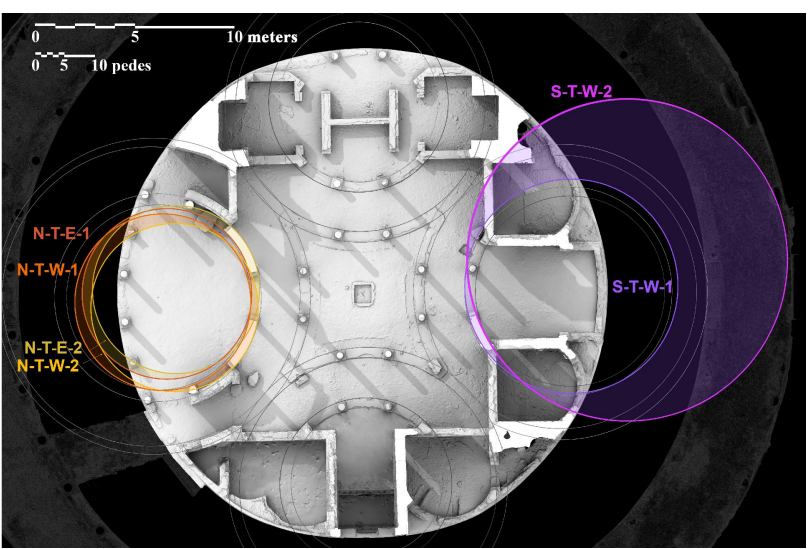

\section{ACKNOWLEDGEMENTS}

The results presented in this paper are part of a wider ongoing research carried out in collaboration between the Direction of Hadrian's Villa and the University of Bologna. Authors would like to thank Sergio Di Tondo (MicroGeo s.r.l.) and Filippo Fantini (Dept. of Architecture, Alma Mater Studiorum University of Bologna) for technical advice during the surveying campaigns since September 2009, on both friezes and archaeological remains. Thanks to the kind cooperation of other collaborators/tutors who carried out several surveying campaigns during the last years: Silvia Bertacchi, Simone Vianello and Simone Rostellato. Authors thank Vincenza Carollo for semantics/meshing of the Maritime Theatre.

Figure 13. Circumferences of reconstructed entablature 


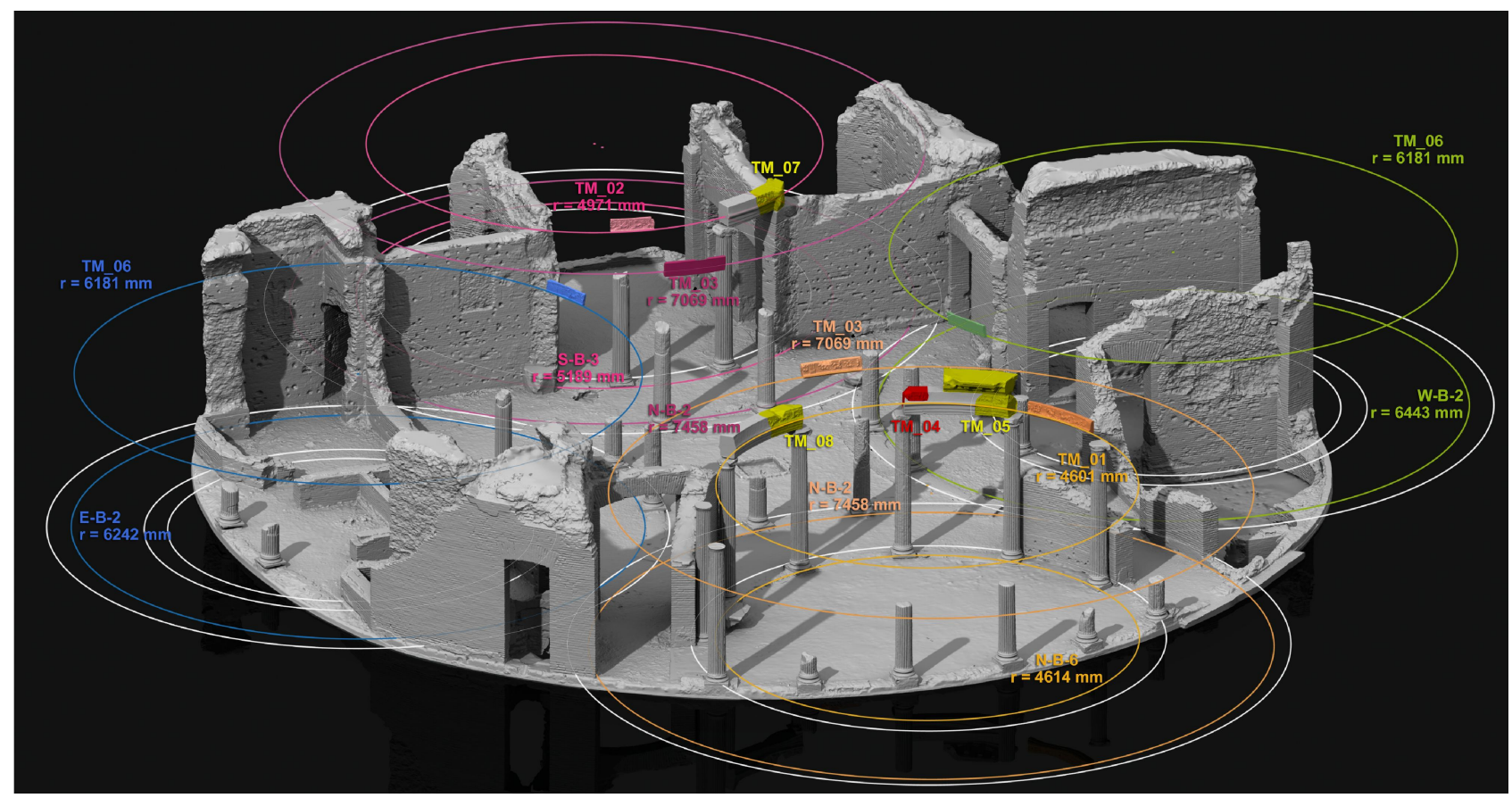

Figure 14. Hypothesis of the virtual anastylosis of some friezes

\section{REFERENCES}

Adembri, B. 2013. Villa Adriana, Villa d'Este e il reimpiego: i fregi figurati curvilinei del teatro Marittimo e di Piazza d'Oro. In: Cogotti, M., Fiore, F.P. (eds.), Ippolito II d'Este, cardinale, principe, mecenate. De Luca Editori d'Arte, RM, pp. 351-366.

Adembri, B., Cipriani, L., Fantini, F., Bertacchi, S. 2015. Reverse designing: an integrated method for interpreting ancient architecture, SCIRES-IT, Volume 5, Issue 2, pp. 15-32.

Adembri, B., Di Tondo, S., Fantini, F. 2015. Architecture with concave and convex rhythms and its decoration in Hadrian age: the Maritime Theatre and the southern pavilion of Piazza d'Oro in Hadrian's Villa. In: Proceedings of ASMOSIA X, Rome, 2126 May 2012), «L'Erma» di Bretschneider, Roma, pp. 3-12.

Aita, D., Barsotti, R., Bennati, S., Caroti, G., Piemonte, A. 2017. 3-dimensional geometric survey and structural modelling of the dome of Pisa Cathedral. Int. Arch. Photogramm. Remote Sens. Spatial Inf. Sci., Volume XLII-2/W3, 2017, 3D Virtual Reconstruction and Visualization of Complex Architectures, 13 March 2017, Nafplio, Greece, pp. 39-46.

Apollonio, F., Gaiani, M., Manferdini, A. M. 2010. Modellazione semantica metodi a multirisoluzione. In: Benedetti, B., Gaiani, M., Remondino, F. (eds.), Modelli digitali $3 D$ in archeologia: il caso di Pompei, Edizione della Normale, Pisa, pp. 236-269.

Aurigemma, S. 1961. Villa Adriana. Ist. Poligrafico dello Stato, Roma.

Canciani, M., Falcolini, C., Buonfiglio, M., Pergola, S., Saccone, M., Mammì, B., Romito, G. 2013. A method for virtual anastylosis: the case of the Arch of Titus at the Circus Maximus in Rome. ISPRS Annals of Photogrammetry, Remote Sensing and Spatial Information Sciences, Volume II-5/W1, 2013, pp. 61-66.
Cipriani, L., Fantini, F. 2017. Digitalization culture vs archaeological visualization: integration of pipelines and open issues. Int. Arch. Photogramm. Remote Sens. Spatial Inf. Sci., XLII-2/W3, pp. 195-202.

Cipriani, L., Fantini, F., Bertacchi, S. 2016. Ch. 10 - 3D Digital Models for Scientific Purpose: Between Archaeological Heritage and Reverse Modelling. In: Ippolito, A. (ed.), Handbook of Research on Emerging Technologies for Architectural and Archaeological Heritage, IGI Global, Hershey, pp. 291-321.

Guidi, G., Russo, M., Beraldin, J.A. 2010. Acquisizione 3De modellazione poligonale. McGraw-Hill, New York.

Ippolito, A. 2015. Digital documentation for archaeology. case studies on etruscan and roman heritage, In: SCIRES-IT, Volume 5, Issue 2, pp. 71-90.

MacDonald. W. L., Pinto J.A. 1995. Hadrian's Villa and Its Legacy. Yale University Press, New Haven.

Scopigno, R., Callieri, M., Cignoni, P., Corsini, M., Dellepiane, M., Ponchio, F., Ranzuglia, G. 2011. 3D Models for Cultural Heritage: Beyond Plain Visualization. Computer, vol. 44, no. 7, July 2011. pp. 48-55.

Thuswaldner, B., Flöry, S., Kalasek, R., Hofer, M., Huang, Q., \& Thür, H. 2009. Digital Anastylosis of the Octagon in Ephesos. JOCCH, 2(1), 1, pp. 1-27.

Üblacker, M. 1985. Das Teatro Marittimo in der Villa Hadriana, Ph. von Zabern, Mainz am Rhein.

Vendrell-Vidal, E., Sánchez-Belenguer, C. 2014. A discrete approach for pairwise matching of archaeological fragments. Journal on Computing and Cultural Heritage (JOCCH), 7(3), 15, pp. 1-18. 